\title{
Utility of Certain Nucleophilic Aromatic Substitution Reactions for the Assay of Ethamsylate in its Dosage forms and in Presence of its Degra- dation Product
}

\author{
F. Belal, M. Sharaf EL-Din, M. M. Tolba, H. Alaa \\ Department of Analytical Chemistry, Faculty of Pharmacy, \\ University of Mansoura , 35516, Mansoura, Egypt. ff_belal@mans.edu.eg \\ Department of Analytical Chemistry, Faculty of Pharmacy, \\ University of Mansoura , 35516, Mansoura, mohiese@mans.edu.eg \\ Department of Analytical Chemistry, Faculty of Pharmacy, \\ University of Mansoura , 35516, Mansoura, manar2kareem@yahoo.com \\ Department of Analytical Chemistry, Faculty of Pharmacy, \\ University of Mansoura, 35516, Mansoura, heba.alaa3@gmail.com
}

\section{ABSTRACT}

The study represents the first report on the development of spectrophotometric methods for determination of ethamsylate (EST) in the presence of hydroquinone as an impurity and/or acidic degradation product. The proposed methods are based on the reaction of EST through it,s secondary amino group either with 1,2-naphthoquinone-4-sulphonate sodium (NQS) at pH 10.7 or 2,4-dinitrofluorobenzene (DNFB) at pH 9.3 to form orange and yellow colored reaction products peaking at 478 and $387 \mathrm{~nm}$ for methods (I) and (II), respectively. The different experimental parameters affecting the development and stability of the reaction products in methods (I) and (II) were carefully studied and optimized. The absorbance-concentration plots were rectilinear over the concentration ranges of 2-30 and 2-14 $\mathrm{gg} \mathrm{mL}-1$ for methods (I) and (II), respectively. The lower detection limits were 0.13 and $0.19 \mu \mathrm{g} \mathrm{mL}-1$ and the lower quantitation limits were 0.44 and $0.63 \mu \mathrm{g} \mathrm{mL}-1$ for methods (I) and (II), respectively. Both methods were successfully applied to commercial ampoules and tablets.

\section{Keywords}

Ethamsylate; hydroquinone; spectrophotometry; naphthoquinone; dinitrofluorobenzene.

\section{Council for Innovative Research}

\section{Journal: Journal of Advances in Chemistry}

Peer Review Research Publishing System

\author{
Vol. 7, No. 1 \\ editor@cirworld.com




\section{Introduction:}

Ethamsylate (EST); is N-ethylethanamine 2,5-dihydroxybenzenesulphonate (Fig. 1). It is a haemostatic agent that appears to maintain the stability of capillary walls and correct abnormal platelets adhesion. It is given for prophylaxis and control of hemorrhages from small blood vessels [1]. The British Pharmacopoeia [2] recommended potentiometric titration method for the determination of EST raw material, using cerium (IV) sulphate as a titrant and a TLC method for detection of it,s known impurity, hydroquinone (HQ) (Fig. 1). In addition, the acid degradation product of EST was reported to be $\mathrm{HQ}$ by Kaul et al [3].

Several analytical methods were developed for the assay of ethamsylate. These methods include; spectrophotometry [48], spectrofluorimetry [9], HPTLC [10], HPLC [3, 11], electrochemical methods [12-15], chemiluminescence [16-19] and capillary electrophoresis [20].

A survey of the literature reveals that, the reported spectrophotometric methods show either low sensitivity or unsuitable linearity range and need tedious extraction procedures [4] and/or suffer from interference due to measurement of absorbance in the near UV region [5]. In addition, no spectrophotometric method has been developed for determination of EST in presence of its degradation product (HQ). Therefore, our target was to develop stability-indicating methods for the analysis of EST in pharmaceutical formulations.

1,2-Naphthoquinone-4-sulphonate sodium and 2,4-Dinitrofluorobenzene have been used as chromogenic reagents for the analysis of many pharmaceuticals [21-25].

\section{Experimental:}

\subsection{Instruments:}

- A Shimadzu UV-Visible 1601 PC Spectrophotometer (Kyoto, Japan) was used for spectrophotometric measurements (P/N 206-67001). The recording range was 0-1.0.

- A Consort NV P901 digital pH Meter (Belgium) calibrated with standard buffers was used for checking the $\mathrm{pH}$ of the buffer solutions.

\subsection{Reagents and materials:}

All the reagents used were of Analytical Reagent grade and distilled water was used throughout the work.

- $\quad$ Ethamsylate (Memphis Chemical CO, Cairo, Egypt).

- $\quad$ Pharmaceutical preparations containing EST were obtained from commercial sources in the local market:

- $\quad$ Dicynone® ampoules; batch \# CDE0953, labeled to contain $250 \mathrm{mg} \mathrm{EST/2} \mathrm{mL.}$

- $\quad$ Dicynone ${ }^{\circledR}$ tablets; batch \# 312265, labeled to contain $250 \mathrm{mg}$ EST/tablet.

- $\quad$ Dicynone ${ }^{\circledR} 500$ tablets; batch \# CDE0876, labeled to contain 500 mg EST/tablet.

- $\quad$ Dicynone® ampoules, Dicynone® 500 tablets (Minapharm, Egypt) and Dicynone® tablets (Memphis Co. for Pharma. \& Chemical Ind., Cairo, Egypt) are manufactured under license of OM PHARMA (Meyrin, Geneva, Switzerland).

- Hydroquinone (El-Nasr Pharmaceutical Chemicals Company (ADWIC), Abu Zaabal, Egypt).

- $\quad$ 1,2-Naphthoquinone-4-sulphonate sodium (Fluka Chemie, Germany) solution was freshly prepared as $0.5 \%$ (w/v) aqueous solution.

- $\quad$ 2,4-Dinitrofluorobenzene (Fluka Chemie, Germany) solution was freshly prepared as $0.3 \%(\mathrm{v} / \mathrm{v})$ in methanol.

- Methanol, hydrochloric acid, sodium hydroxide and boric acid (BDH, UK).

- $\quad$ Borate buffer solutions $(0.2 \mathrm{M})$ were prepared by mixing appropriate volumes of $0.2 \mathrm{M}$ boric acid with $0.2 \mathrm{M}$ sodium hydroxide and adjusting the $\mathrm{pH}$ to 10.7 or 9.3 using $\mathrm{pH}$ Meter.

\subsection{Standard solutions:}

Stock solution of EST was prepared by dissolving $10.0 \mathrm{mg}$ of the drug in $100 \mathrm{~mL}$ of distilled water or methanol for method I or II, respectively. This solution was further diluted with the same solvent as appropriate to obtain the working concentration range. The stock solution is stable for 7 days when kept in the refrigerator. 


\subsection{General recommended procedures:}

\subsubsection{Procedures for calibration graphs:}

\subsection{1.i. Method I:}

To a set of $10 \mathrm{~mL}$ volumetric flasks, appropriate aliquots of the standard working solution were quantitavely transferred, to obtain final concentrations in the range of $2-30 \mu \mathrm{g} \mathrm{mL}-1$. To each flask, $1 \mathrm{~mL}$ of borate buffer solution ( $\mathrm{pH}$ 10.7) followed by $1 \pm 0.2 \mathrm{~mL}$ of NQS solution $(0.5 \%)$ were added and mixed well. The solutions were heated in thermostatically controlled water bath at $60 \pm 5^{\circ} \mathrm{C}$ for $15 \mathrm{~min}$. The reaction was stopped by cooling under tap water, and solutions were completed to the volume with distilled water. The absorbance of the resulting solutions was measured at $478 \mathrm{~nm}$ against a reagent blank prepared simultaneously. The calibration graph was constructed by plotting the absorbance versus the final concentration of the drug. Alternatively, the corresponding regression equation was derived.

\subsection{1.ii. Method II:}

To a set of $10 \mathrm{~mL}$ volumetric flasks, appropriate aliquots of the standard working solution were quantitavely transferred, to obtain final concentrations in the range of 2-14 $\mu \mathrm{g} \mathrm{mL}-1$. To each flask, $0.8 \mathrm{~mL}$ of borate buffer solution (pH 9.3) followed by $2.6 \pm 0.2 \mathrm{~mL}$ of DNFB solution $(0.3 \% \mathrm{v} / \mathrm{v})$ were added and mixed well. The solutions were heated in thermostatically controlled water bath at $75 \pm 5^{\circ} \mathrm{C}$ for $20 \mathrm{~min}$.

The reaction was stopped by cooling under tap water, and then $0.2 \mathrm{~mL}$ of conc $\mathrm{HCl}$ was added and the solutions were made up to volume with methanol. The absorbance was measured at $387 \mathrm{~nm}$ against a reagent blank.

The absorbance was plotted versus the final concentration of the drug to obtain the calibration graph. Alternatively, the corresponding regression equation was derived.

\subsubsection{Assay procedure for analysis of EST/HQ synthetic mixtures:}

Aliquots of EST and HQ standard solutions in different ratios were transferred into a series of $10 \mathrm{~mL}$ volumetric flasks. The procedures described under "Calibration Graphs" were then performed for both methods. The percentage recoveries were calculated by referring to the calibration graphs, or using the corresponding regression equations.

\subsubsection{Assay procedure for dosage forms:}

(a) Procedure for tablets:

Ten tablets (Dicynone ${ }^{\circledR} 250 \mathrm{mg}$ or $500 \mathrm{mg}$ ) were accurately weighed, finely pulverized, and thoroughly mixed. An accurately weighed amount of powdered tablets equivalent to $10.0 \mathrm{mg}$ of EST was transferred into small conical flask and extracted with $3 \times 30 \mathrm{~mL}$ of distilled water for method I or methanol for method II. The extract was filtered into $100 \mathrm{~mL}$ volumetric flask. The conical flask was washed with few $\mathrm{mLs}$ of distilled water or methanol. The washings were passed into the same volumetric flask and completed to the volume with the same solvent. Aliquots of these solutions were transferred into a series of $10 \mathrm{~mL}$ volumetric flasks and the procedures described under " Calibration Graphs" were then performed for both methods. The nominal content of the tablets was determined either from the previously plotted calibration graphs or using the corresponding regression equations.

\section{(b) Procedure for ampoules:}

The contents of five ampoules (Dicynone®) were mixed well. An aliquot of the solution equivalent to $125.0 \mathrm{mg}$ EST was transferred into $25 \mathrm{~mL}$ volumetric flask. The solution was diluted to the mark with distilled water or methanol for method I or II, respectively.

Then, $4 \mathrm{~mL}$ were transferred into $100 \mathrm{~mL}$ volumetric flask. Aliquots of these solutions were quantitavely transferred into a series of $10 \mathrm{~mL}$ volumetric flasks and the procedures described under "Calibration Graphs" were then applied for both methods. The nominal content of the ampoules was determined either from the previously plotted calibration graph or using the corresponding regression equation.

\section{Results and Discussion:}

The chemical structure of EST and HQ are closely related. Therefore, the determination of EST in presence of $\mathrm{HQ}$ is a challenging problem. However, the presence of secondary amino group in the chemical feature of EST only which is susceptible to derivatization with nucleophilic reagents such as NQS or DNFB, initiated the present study and allowed the determination of EST in presence of $\mathrm{HQ}$ without any interference.

Ethamsylate was found to react with NQS in borate buffer of $\mathrm{pH} 10.7$ yielding a highly colored orange reaction product with maximum absorbance at $478 \mathrm{~nm}$ (Fig. 2).

Also, the drug was found to react with DNFB in borate buffer of $\mathrm{pH} 9.3$ and a yellow colored reaction product with maximum absorbance at $387 \mathrm{~nm}$ was formed (Fig. 2). 


\subsection{Study of experimental parameters:}

The experimental conditions were optimized by varying each in turn while keeping all others constant. These variables include; effect of $\mathrm{pH}$ and volume of buffer, effect of the concentration of reagents, effect of heating temperature and heating times, effect of diluting solvent and effect of time on stability of the reactions products.

\subsubsection{Effect of $\mathrm{pH}$ and volume of buffer:}

According to the literature, the reaction of amines with NQS and DNFB was carried out in alkaline medium.

So, the influence of $\mathrm{pH}$ on the formation of the reactions products was studied over the range of $6.0-12.0$ using $0.2 \mathrm{M}$ borate buffer solution. Maximum and constant absorbance intensities were achieved at $\mathrm{pH} 10.7 \pm 0.5$ for method $\mathrm{I}$ and $9.3 \pm 0.2$ for method II. Therefore, $\mathrm{pH} 10.7$ and 9.3 were chosen as the optimum $\mathrm{pH}$ values for methods I and II, respectively (Fig. 3).

Maximum absorbance intensities were achieved using $1.0 \pm 0.2 \mathrm{~mL}$ or $0.8 \pm 0.3 \mathrm{~mL}$ of borate buffer solutions for methods I and II, respectively (Fig. 4). So that, $1.0 \mathrm{~mL}$ of borate buffer solution of $\mathrm{pH} 10.7$ and $0.8 \mathrm{~mL}$ of borate buffer solution of $\mathrm{pH} 9.3$ were chosen as the optimum buffer volumes for methods I and II, respectively.

\subsubsection{Effect of the concentration of reagents solutions:}

The influence of the reagents concentrations was studied using different volumes of either $0.5 \% \mathrm{w} / \mathrm{v}$ solution of NQS (method I) or $0.3 \% \mathrm{v} / \mathrm{v}$ solution of DNFB (method II). It was found that, increasing volumes of the reagents produced a proportional increase in the absorbance values. Maximum and constant absorbance intensities were achieved using volumes of the reagents ranged from $0.8-1.2$ or $2.4-2.8 \mathrm{~mL}$ of NQS or DNFB for method I or II, respectively. Further increase of the reagents volumes produced gradual decrease in the absorbance intensities. Therefore, $1.0 \pm 0.2 \mathrm{~mL}$ of $0.5 \%$ $\mathrm{w} / \mathrm{v}$ NQS solution and $2.6 \pm 0.2 \mathrm{~mL}$ of $0.3 \% \mathrm{v} / \mathrm{v}$ DNFB solution were chosen as the optimal volumes of the reagents for methods I and II, respectively (Fig. 5). In method II, addition of $0.2 \mathrm{~mL}$ of conc HCL is essential to remove excess DNFB reagent which interferes with the measurement of reaction product. Where, the excess DNFB is acid hydrolyzed to the colorless 2,4-dinitrophenol allowing the determination of EST-DNFB derivative which remains stable.

\subsubsection{Effect of temperature and heating time:}

Preliminary studies showed that the reaction rates were very slow at room temperature in both methods. So, the reactions were performed in a thermostatically controlled water bath at different temperature settings ranging from (25$100^{\circ} \mathrm{C}$ ) for various time intervals. For both methods, the results revealed that increasing the temperature resulted in an increase in the absorbance values of the reactions products. The maximum absorbance values were attained at $55-65{ }^{\circ} \mathrm{C}$ with in $15 \mathrm{~min}$ and $70-80^{\circ} \mathrm{C}$ with in $20 \mathrm{~min}$ for methods I and II, respectively (Fig. 6, 7). At higher temperatures, the absorbance of the reaction product decreased gradually in case of method I, while precipitation in the method II was observed. The decrease in the absorbance was probably attributed to the instability of the EST derivatives at higher temperatures. Therefore, the studies were carried out at 60 and $75^{\circ} \mathrm{C}$ for methods I and II, respectively.

\subsubsection{Effect of diluting solvent:}

The effect of diluting solvent on the absorbance intensities of the reaction products was tested using different solvents viz water, methanol, ethanol, acetone, acetonitrile and dimethylformamide. Using water and methanol as diluting solvents gave the highest absorbance values and more reproducible results for methods I and II, respectively. So, they were selected as the best solvents.

\subsubsection{Effect of time on stability of the reactions products:}

Regarding the stability of the produced derivatives, both were found to be stable at room temperature for approximately 1 hour.

\subsection{Validation of the proposed methods:}

The validity of the proposed methods was tested regarding linearity, specificity, accuracy, repeatability and intermediate precision according to ICH Q2(R1) recommendations [26].

\subsubsection{Linearity:}

The calibration graphs obtained by plotting the values of the absorbance versus the final concentrations of the drug $(\mu \mathrm{g} \mathrm{mL}-1)$ were found to be rectilinear over the concentration ranges cited in Table 1.

The validity of the methods was proved by statistical evaluation of the regression data, regarding the standard deviation of the residuals (Sy/x), the standard deviation of the intercept (Sa) and standard deviation of the slope $\mathrm{Sb}$ (Table 1). The small values of the figures indicate low scattering of the points around the calibration line and high precision. 


\subsubsection{Limit of Quantitation and Limit of Detection:}

Limit of Quantitation (LOQ) and Limit of Detection (LOD) were calculated according to ICH Q2(R1) recommendation using the following equations [26]:

$$
\begin{aligned}
\mathrm{LOQ} & =10 \mathrm{Sa} / \mathrm{b} \\
\mathrm{LOD} & =3.3 \mathrm{Sa} / \mathrm{b}
\end{aligned}
$$

Where $\mathrm{Sa}$ is the standard deviation of the intercept of regression line, and $\mathrm{b}$ is the slope of the regression line. The values of LOD and LOQ for both methods are abridged in Table 1.

\subsubsection{Accuracy:}

To test the validity of the proposed methods, they were applied to the determination of pure sample of EST over the concentration ranges cited in Table 1. The results obtained were in good agreement with those obtained using the comparison method [6]. Statistical analysis of the result obtained using Student t-test and the variance ratio F-test [27] revealed no significance differences between the proposed and comparison methods regarding the accuracy and precision, respectively (Table 2). The comparison method is based on reaction of EST with 3-methyl-2-benzothiazolinone hydrazone hydrochloride in presence of cerium (IV) ammonium sulfate at room temperature for 20 min and measuring and the absorbance of the reaction product at $514 \mathrm{~nm}[6]$.

\subsubsection{Precision:}

\subsection{4.i. Repeatability (intra-day):}

The repeatability was performed over the specific concentration ranges through replicate analysis of three concentrations of EST in pure form on three successive occasions. The results are presented in Table 3.

\subsection{4.ii. Intermediate precision (inter-day):}

Intermediate precision was tested by repeated analysis of EST in pure form using the concentrations shown in Table 3 for a period of 3 successive days.

(Table 3).

High \% recovery and low \% RSD indicate high accuracy and precision of theproposed methods, respectively

\subsubsection{Robustness:}

The robustness of the procedures adopted in the two proposed methods was demonstrated by the constancy of the absorbance intensity with the deliberated minor changes in the experimental parameters.

For method $\mathrm{I}$, the changes included the $\mathrm{pH}$ of borate buffer solution, $10.7 \pm 0.5$, the change in the volume of the buffer solution, $1.0 \pm 0.2 \mathrm{~mL}$, the change in the volume of NQS $(0.5 \% \mathrm{w} / \mathrm{v}), 1.0 \pm 0.2$, the change in the heating temperature, $60 \pm 5^{\circ} \mathrm{C}$ and the change in the heating time, $15 \pm 5 \mathrm{~min}$.

Meanwhile, for method II these changes included the $\mathrm{pH}$ of borate buffer solution, $9.3 \pm 0.2$, the change in the volume of the buffer solution, $0.8 \pm 0.3 \mathrm{~mL}$, the change in the volume of DNFB $(0.3 \% \mathrm{v} / \mathrm{v}), 2.6 \pm 0.2 \mathrm{~mL}$, the change in the heating temperature, $75 \pm 5^{\circ} \mathrm{C}$ and the change in the heating time, $20 \pm 5 \mathrm{~min}$. These minor changes that may take place during the experimental operation didn't affect the absorbance of the reaction products.

\subsubsection{Selectivity:}

The selectivity of the methods was investigated by observing any interference encountered from the common tablets excipients and ampoules. It was found that, these excipients didn,t interfere with the results of the proposed methods (Table 4).

\subsection{Analysis of EST/HQ synthetic mixtures:}

Methods I and II were applied to the simultaneous determination of EST and HQ in synthetic mixtures containing different ratios of both compounds. The concentrations of both compounds in the synthetic mixture were calculated according to the linear regression equations. The results indicate the accuracy of the proposed methods as shown in Table 5.

\subsection{Pharmaceutical Applications:}

The proposed methods were successfully applied to the determination of the studied drug in its pharmaceutical preparations. The results obtained were statistically compared to those of the comparison method [6] using Student's t-test for accuracy and the variance ratio F-test for precision, respectively (Table 4). The results obtained indicate no significant difference between the proposed methods and the comparison one.

\subsection{Molar ratio and mechanism of the reaction:}

The stoichiometry of the reactions in the two methods was studied adopting the limiting logarithmic method [28]. Plots of log absorbance versus log [reagent] and log [drug] gave straight lines. The slopes of which were 1.1 and 0.8 for NQS and EST in method I, respectively (Fig. 8). While, the slopes were 0.7 and 0.9 for DNFB and EST in method II, re- 
spectively (Fig. 8). Hence, It is concluded that the reactions proceed in the ratio of $1: 1$, confirming that one molecule of the drug condenses with one molecule of NQS or DNFB in method I or II, respectively.

Based on the absorbed molar ratio, proposed reaction pathway are given in sheme 1 and 2 .

\section{Conclusion}

The present study described for the first time, a successful analysis of EST in the presence of it,s acidic degradation product Hydroquinone with simple spectrophotometric methods. These methods could be used for determination of EST in pure form and pharmaceutical dosage forms. They were found to be sensitive, accurate and don,t need expensive sophisticated instrument. Moreover, the reproducibility as well as convenience makes the two proposed methods suitable for routine analysis in quality control laboratories.

Table (1): Analytical performance data for the proposed methods.

\begin{tabular}{|c|c|c|}
\hline Parameter & Method I & Method II \\
\hline Linearity range $(\mu \mathrm{g} / \mathrm{mL})$ & $2.0-30.0$ & $2.0-14.0$ \\
\hline Intercept (a) & $4.47 \times 1$ & $3.93 \times 10^{-3}$ \\
\hline Slope (b) & $2.38 \times 10^{-2}$ & $5.77 \times 10^{-2}$ \\
\hline Correlation coefficient ( $r$ ) & 0.9999 & 0.9999 \\
\hline S.D. of residuals $(\mathrm{Sy} / \mathrm{x})$ & $2.27 \times 10^{-3}$ & $4.73 \times 10^{-3}$ \\
\hline S.D. of intercept (Sa) & $1.04 \times 10^{-3}$ & $3.62 \times 10^{-3}$ \\
\hline S.D. of slope (Sb) & $9.5 \times 10^{-5}$ & $4.57 \times 10^{-1}$ \\
\hline $\begin{array}{l}\text { Percentage relative standard dev- } \\
\text { iation, \% RSD }\end{array}$ & 1.23 & 0.69 \\
\hline Percentage relative error, \% Error & 0.50 & 0.52 \\
\hline Limit of detection, LOD $(\mu \mathrm{g} / \mathrm{mL})$ & 0.13 & 0.19 \\
\hline Limit of quantitation, $\mathrm{LOQ}(\mu \mathrm{g} / \mathrm{mL})$ & 0.4 & 0.63 \\
\hline Molar absorptivity, $\varepsilon$ (L/mol./cm.) & 6250 & 15349 \\
\hline
\end{tabular}


Table (2): Application of the proposed and comparison methods to the determination of ethamsylate in pure form.

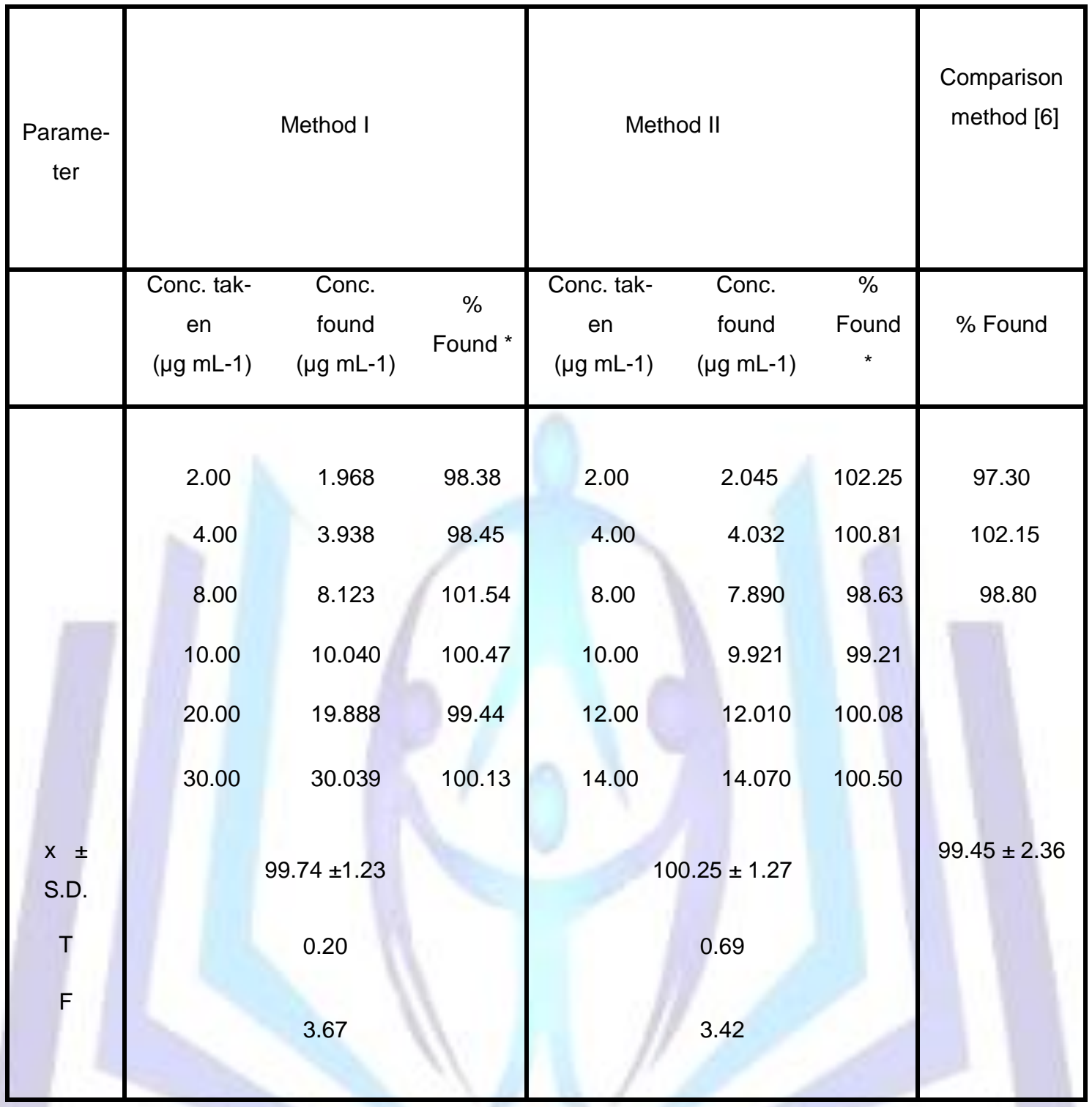

* Each result is the average of three seperate determinations.

- The tabulated $t$ and $F$ values are 3.36 and 5.79 at $p=0.05$, respectively [28]. 
Table (3): Precision data for the determination of EST by the propose methods.

\begin{tabular}{|c|c|c|c|}
\hline $\begin{array}{c}\text { Amount taken } \\
(\mu \mathrm{g} / \mathrm{mL})\end{array}$ & $\%$ Found & $\%$ RSD & $\%$ Error \\
\hline Method I & & & \\
\hline Intraday & & & \\
\hline 8.0 & $98.91 \pm 0.51$ & 0.52 & 0.30 \\
\hline 10.0 & $99.61 \pm 0.68$ & 0.68 & 0.39 \\
\hline 20.0 & $99.09 \pm 1.87$ & 1.89 & 1.09 \\
\hline Interday & & & \\
\hline 8.0 & $99.38 \pm 0.88$ & 0.89 & 0.51 \\
\hline 10.0 & $102.03 \pm 0.05$ & 0.05 & 0.03 \\
\hline 20.0 & $100.47 \pm 2.33$ & 2.32 & 1.34 \\
\hline Method II & & & \\
\hline Intraday & & & \\
\hline 8.0 & $99.41 \pm 0.70$ & 0.70 & 0.40 \\
\hline 10.0 & $99.38 \pm 0.84$ & 0.85 & 0.49 \\
\hline 12.0 & $99.44 \pm 1.93$ & 1.94 & 1.12 \\
\hline Interday & & & \\
\hline 8.0 & $99.48 \pm 0.32$ & 1.33 & 0.77 \\
\hline 10.0 & $100.15 \pm 1.32$ & 1.32 & 0.76 \\
\hline 12.0 & $100.6 \pm 0.57$ & 0.57 & 0.33 \\
\hline
\end{tabular}

$N$. B. Each result is the average of three separate determinations. 
Table (4): Assay results for the determination of EST in dosage forms by the proposed and comparison methods.

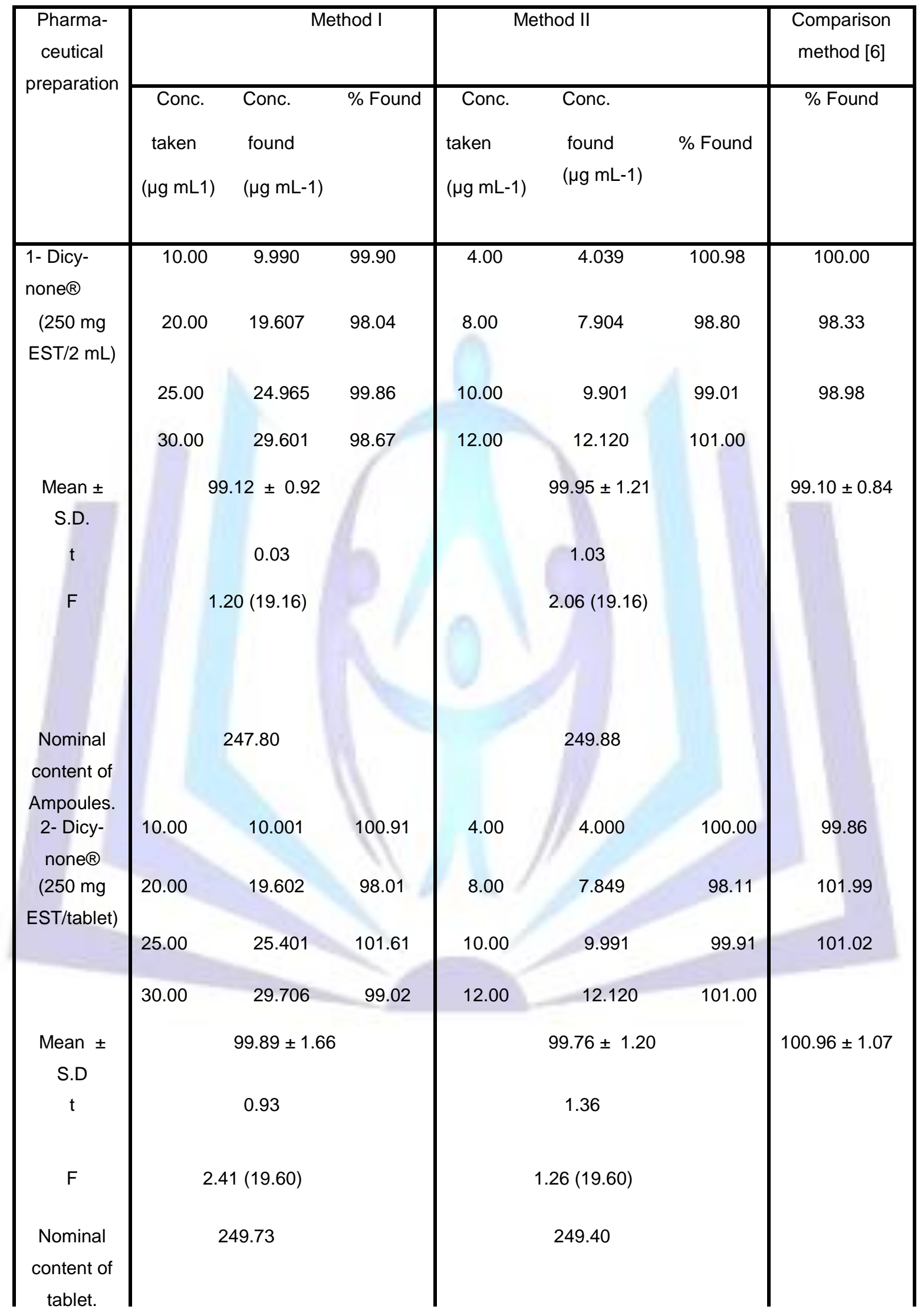




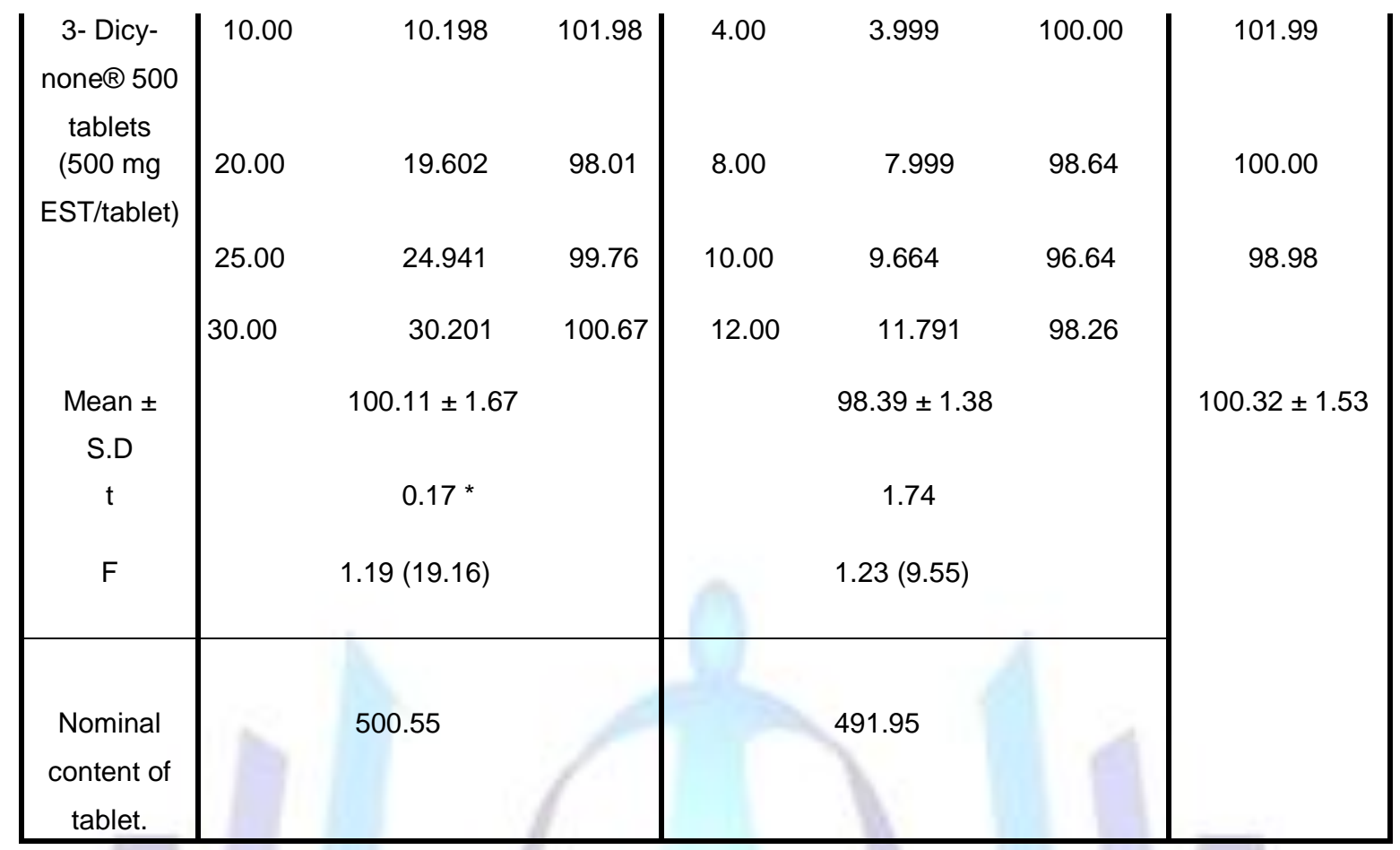

All the pharmaceutical preparations are manufactured under license of OM PHARMA, Switzerland. N.B. Each result is the average of three separate determinations.

* The tabulated $t$ value is 2.57 at $p=0.05$ [27].

Table (5): Application of the proposed methods for the determination of EST in presence of hydroquinone.

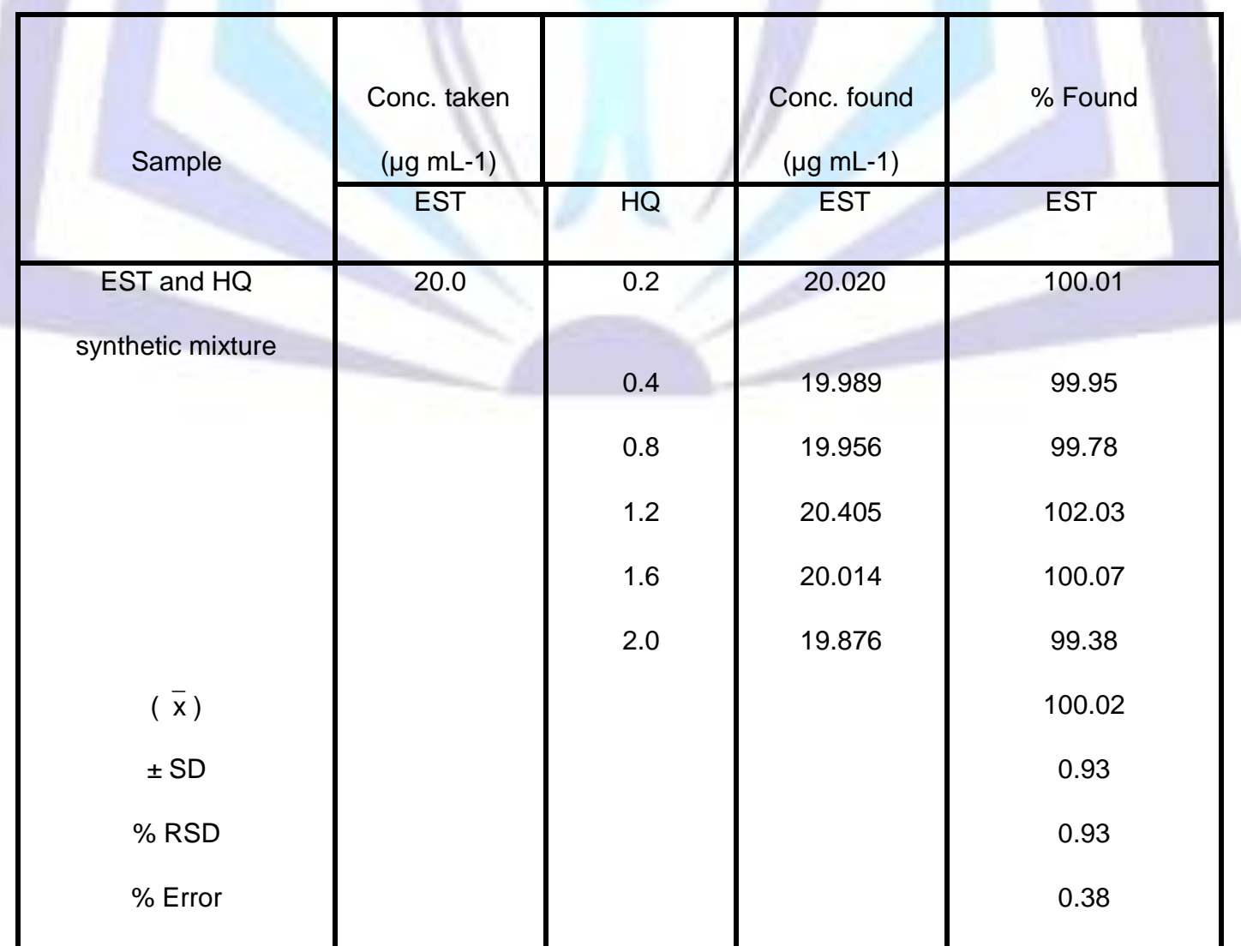




\begin{tabular}{|c|c|c|c|c|} 
& 10.0 & 0.1 & 9.990 & 99.90 \\
& 0.2 & 10.089 & 100.89 \\
& 0.4 & 9.958 & 99.58 \\
& 0.6 & 9.907 & 99.07 \\
& 0.8 & 10.057 & 100.57 \\
& 1.0 & 10.023 & 100.23 \\
& & & & 100.04 \\
& & & 0.67 \\
& & & 0.67 \\
& & & & 0.27 \\
\hline \% ESD & & & & \\
\hline
\end{tabular}

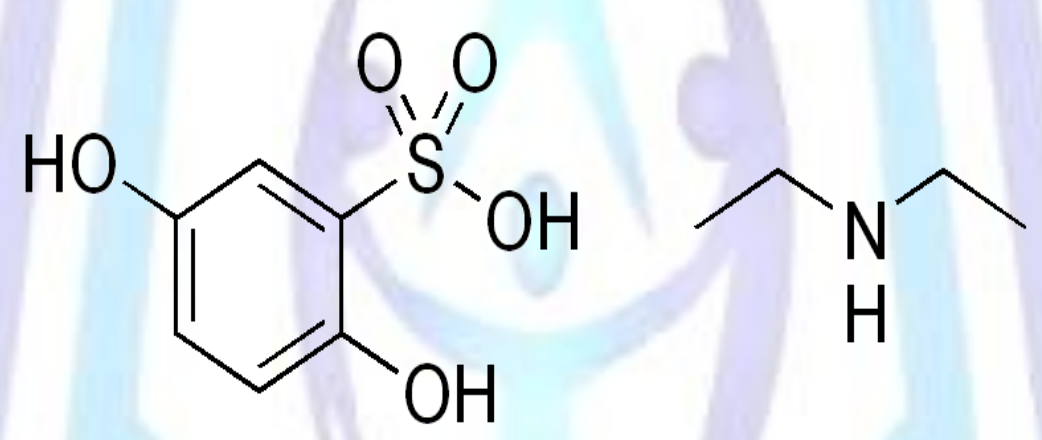

Ethamsylate

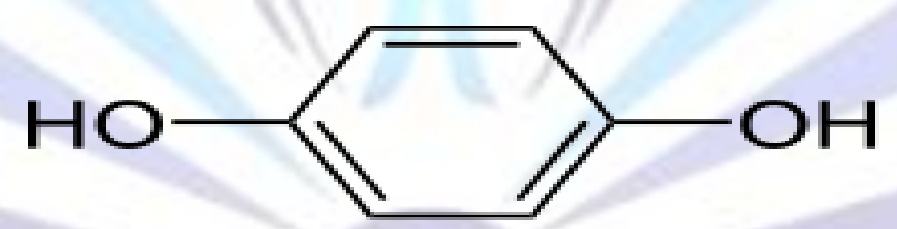

Hydroquinone

Fig. (1): Structure formulae of the studied drugs. 


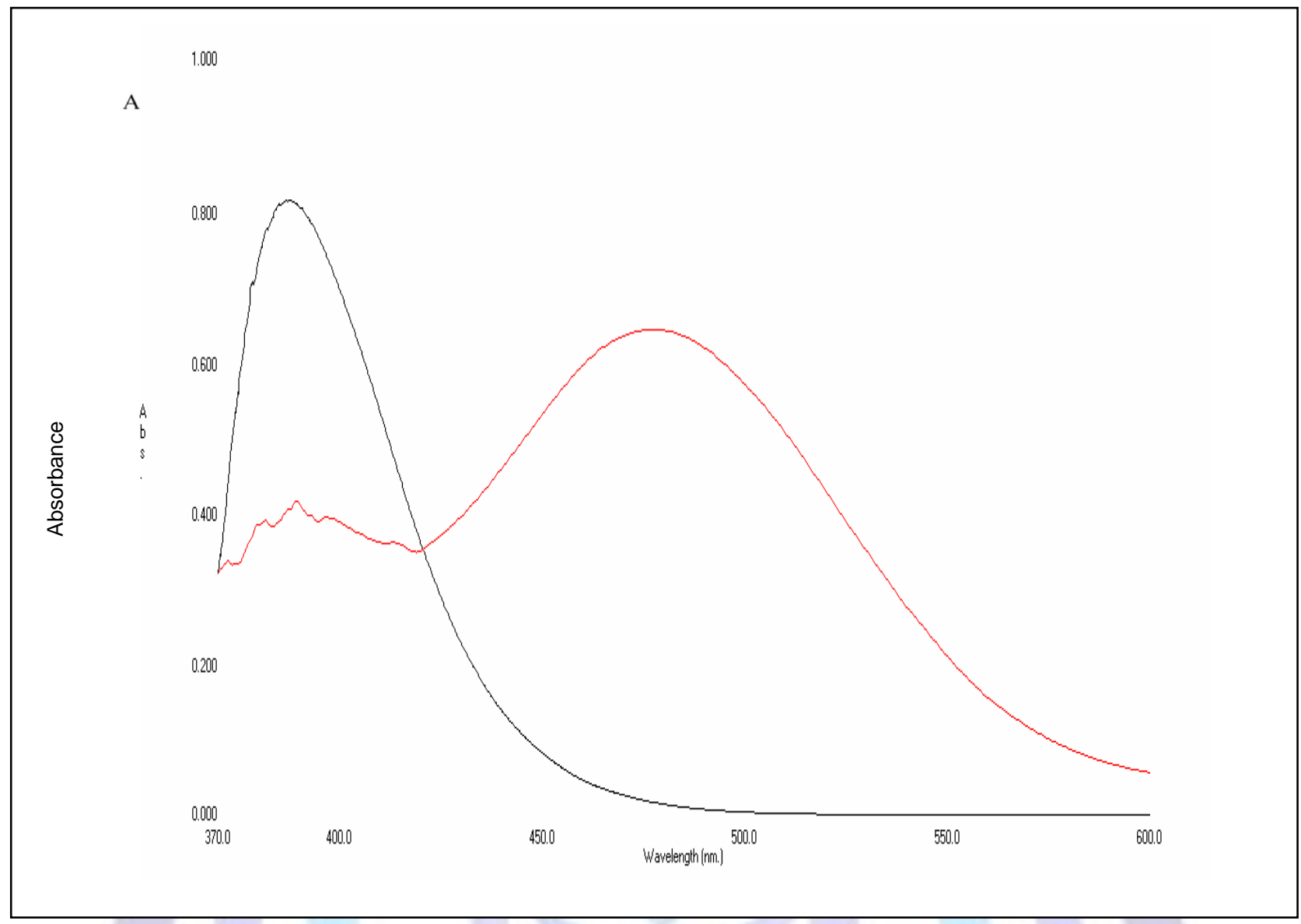

Fig. (2): Absorption spectra of

(A) reaction product of ethamsylate (30 $\mu \mathrm{g} \mathrm{mL-1)}$ with NQS at $\mathrm{pH} 10.7$.

(B) reaction product of ethamsylate $(14 \mu \mathrm{g} \mathrm{mL}-1)$ with DNFB at $\mathrm{pH} 9.3$. 


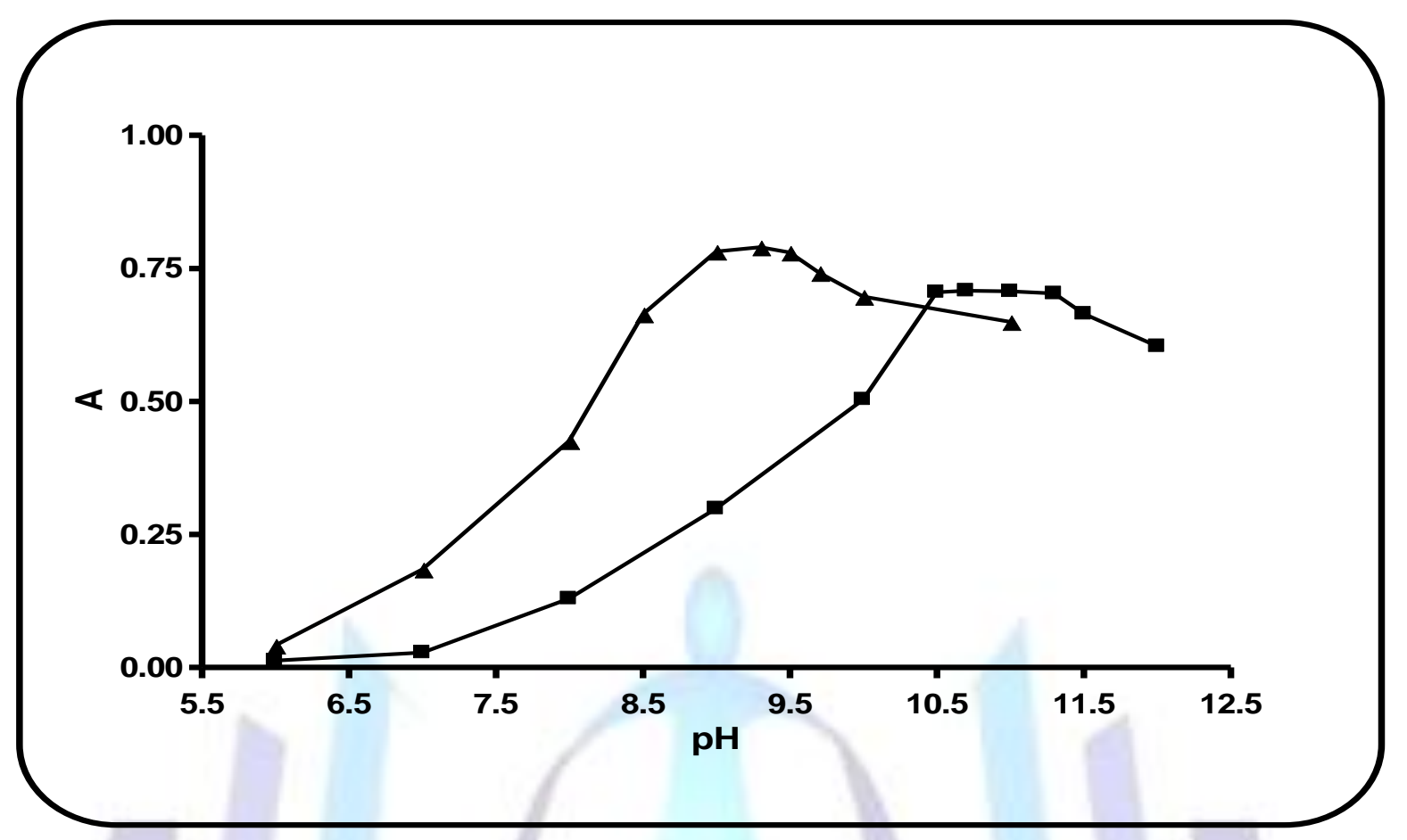

Fig. (3):

Effect of $\mathrm{pH}$ on the absorbance of the reactions products of

Ethamsylate $(30 \mu \mathrm{g} \mathrm{mL}-1)$ with NQS (method I).

$\triangle$ Ethamsylate (14 $\mu \mathrm{g} \mathrm{mL-1)}$ with DNFB (method II).

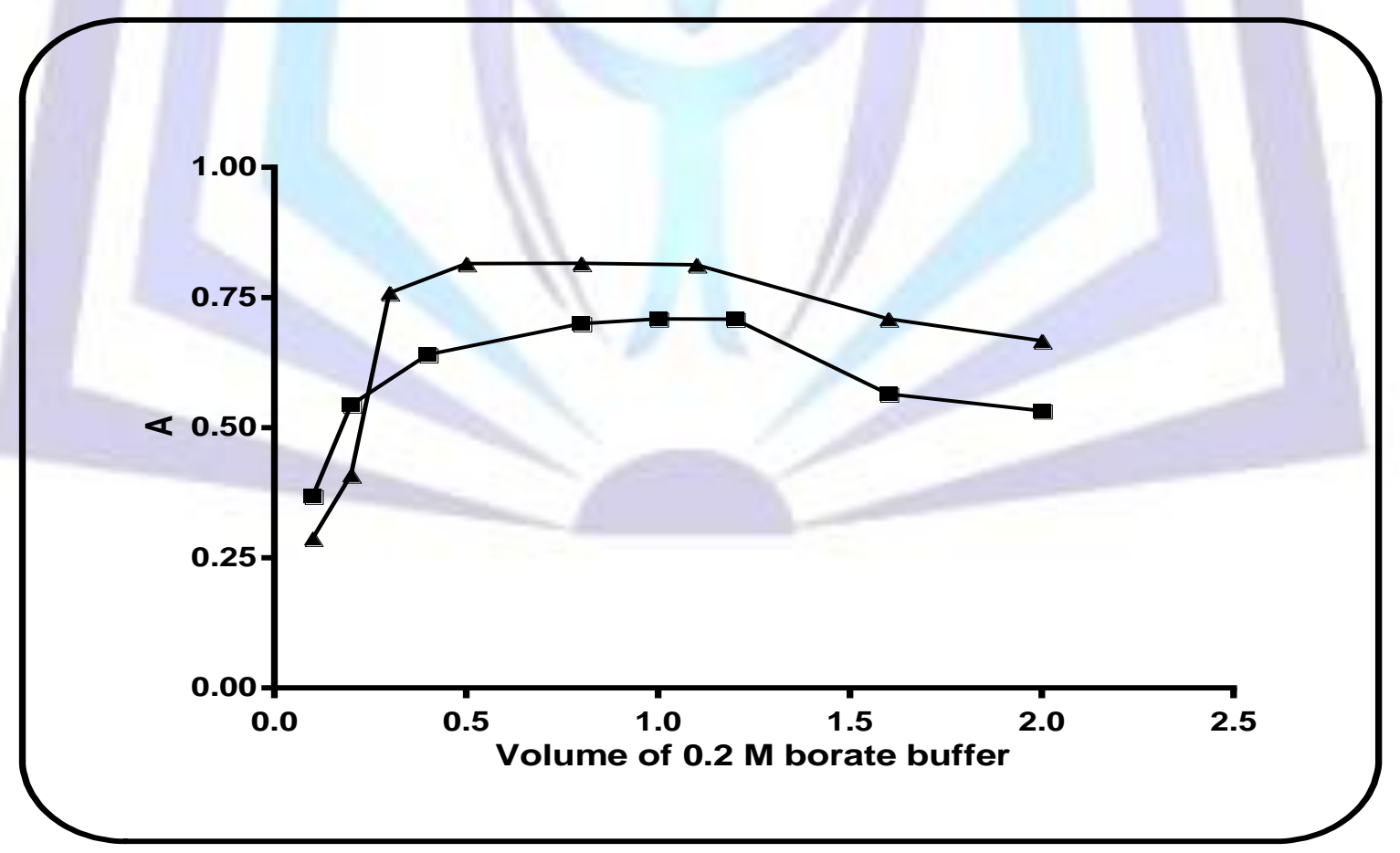

Fig. (4):

Effect of volume of $0.2 \mathrm{M}$ borate buffer on the absorbance of the reactions products of Ethamsylate $(30 \mu \mathrm{g} \mathrm{mL}-1)$ with NQS (method I).

$\triangle$ Ethamsylat (14 $\mu \mathrm{g} \mathrm{mL-1)}$ with DNFB (method II). 


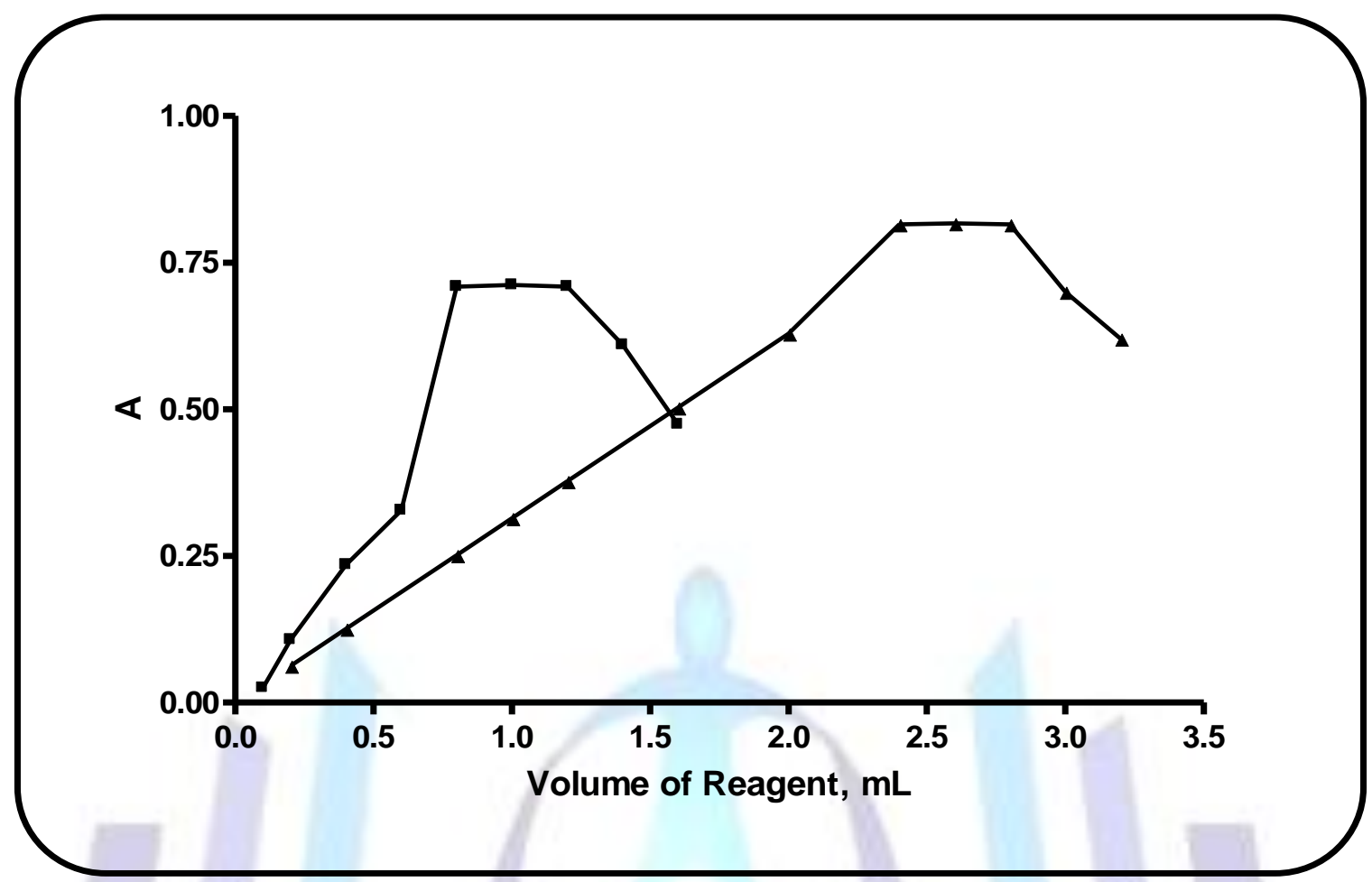

Fig. (5):

Effect of volume of the reagents on the absorbance of the reactions products of

- Ethamsylate (30 $\mu \mathrm{g} \mathrm{mL}-1)$ with NQS (method I).

$\triangle$ Ethamsylate $(14 \mu \mathrm{g} \mathrm{mL}-1)$ with DNFB (method II).

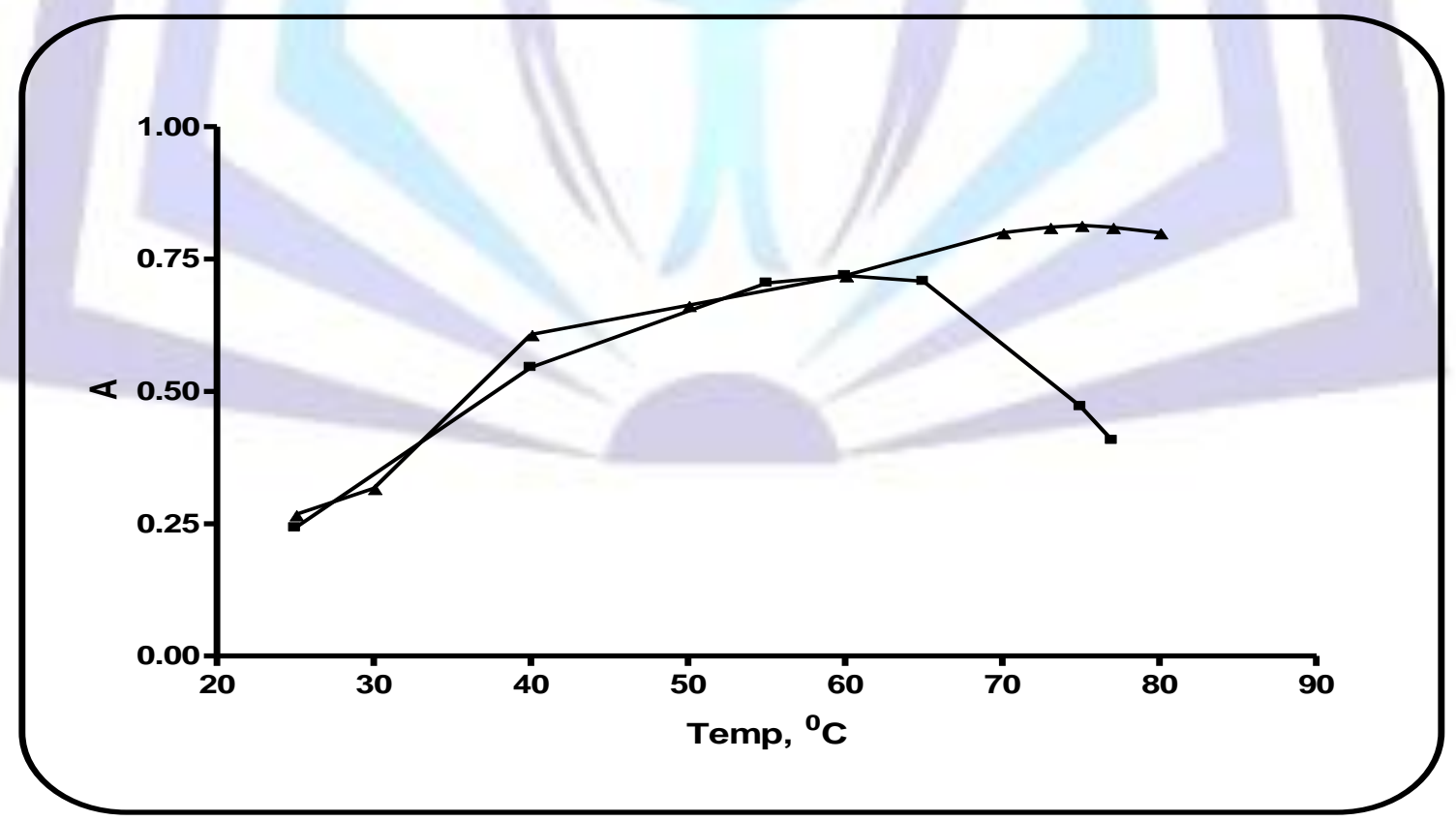

Fig. (6):

Effect of heating temperature on the absorbance of the reactions products

Ethamsylate (30 $\mu \mathrm{g} \mathrm{mL-1)}$ with NQS for 15 min (method I).

$\triangle$ Ethamsylate (14 $\mu \mathrm{g} \mathrm{mL-1)}$ with DNFB for $20 \mathrm{~min}$ (method II ). 


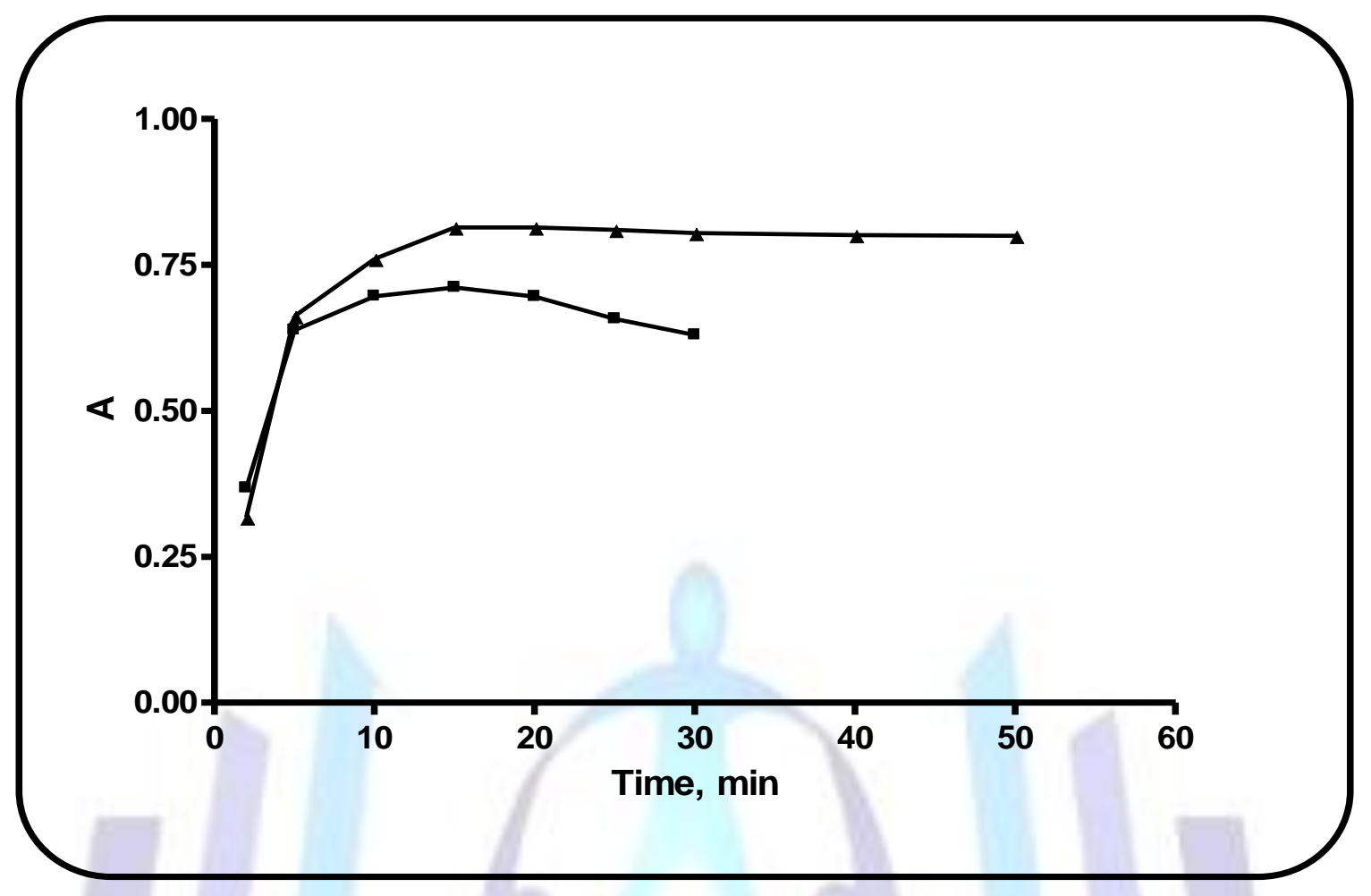

Fig. (7):

Effect of heating time on the absorbance of the reactions products Ethamsylate (30 $\mu \mathrm{g} \mathrm{mL-1)}$ with NQS (method I).

$\triangle$ Ethamsylate (14 $\mu \mathrm{g} \mathrm{mL-1)}$ with DNFB (method II).

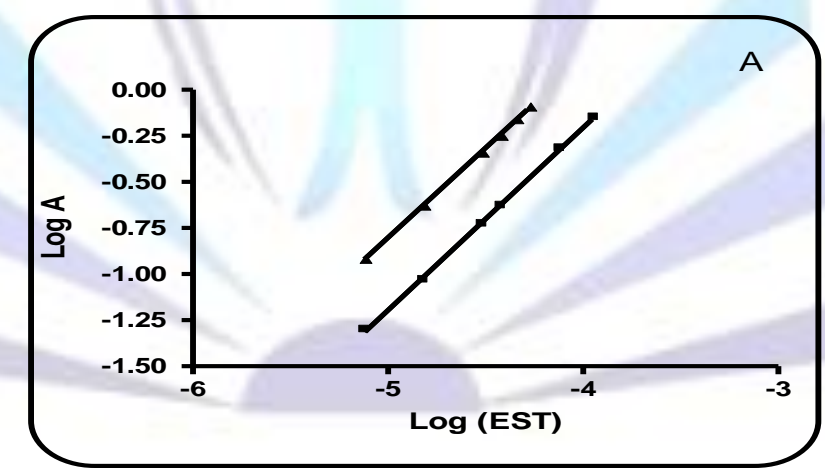

Method II $\boldsymbol{\Delta}$ Method I 


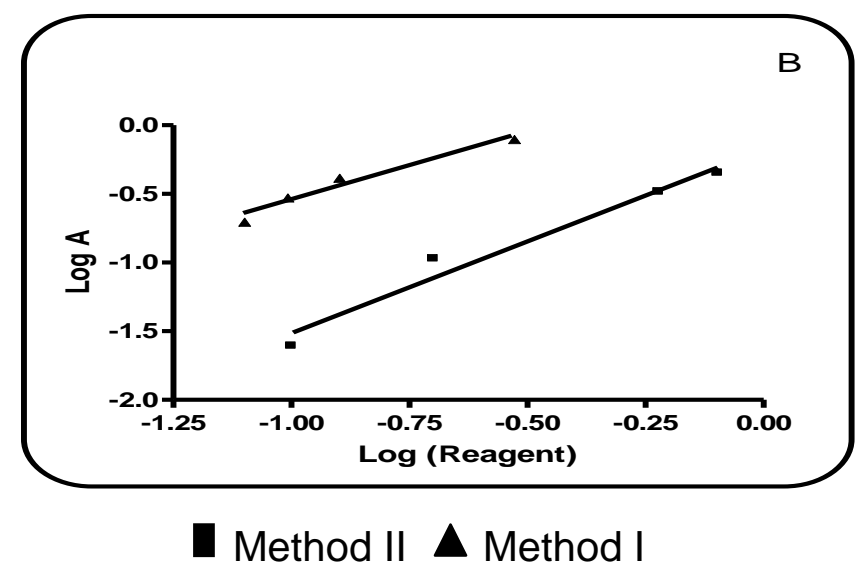

Fig. (8):

Limiting logarithmic plots for the molar reactivity of EST with the reagents:

(A) Log A vs Log [EST] when [reagent] is kept constant.

(B) Log A vs Log [reagent] when [EST] is kept constant.

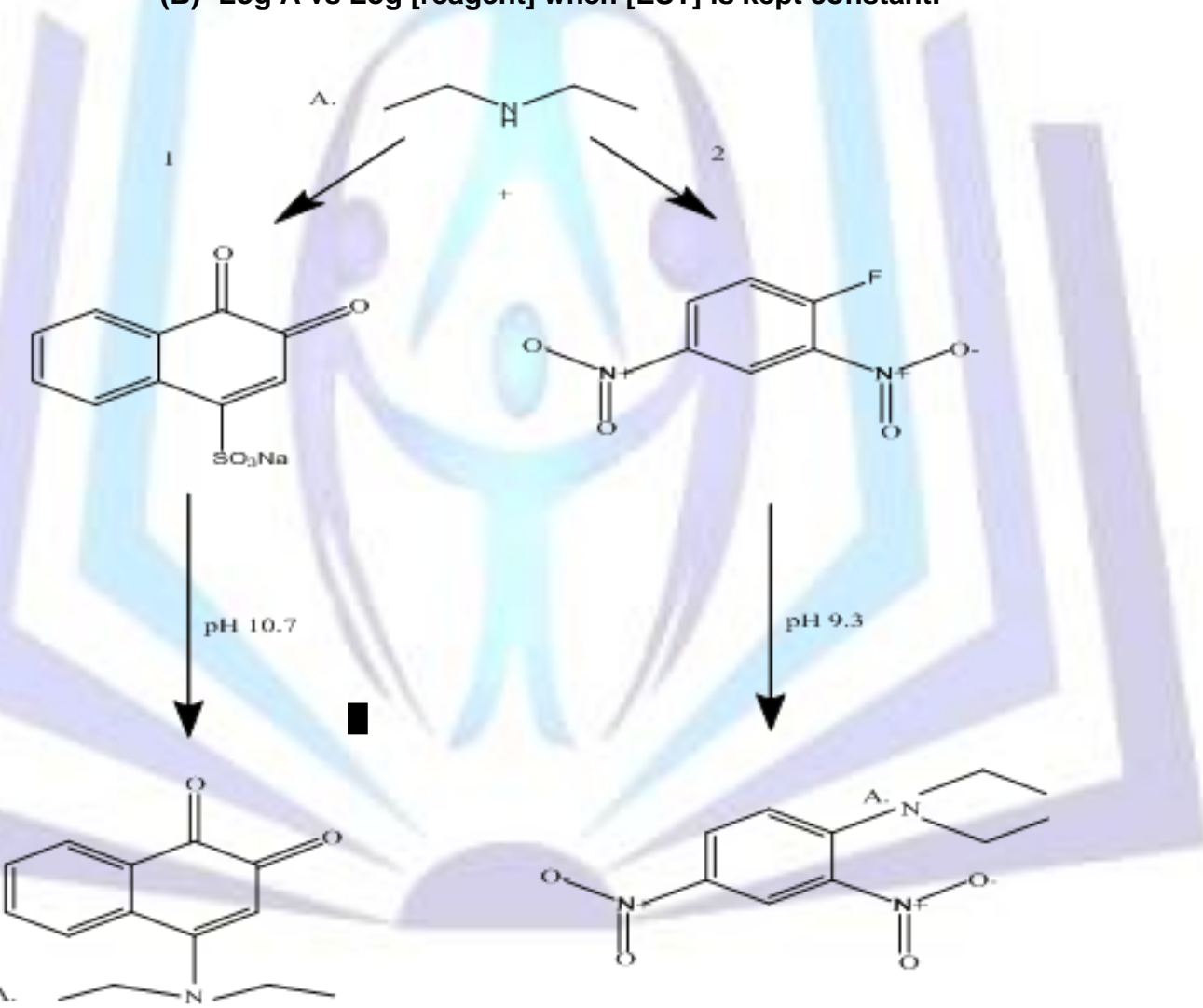<smiles>O=S(=O)(O)c1cc(O)ccc1O</smiles>

\section{Scheme}

1-Proposed reaction pathway between ethamsylate and 1, 2-Naphthoquinone-4-sulphonate sodium under the described reaction condition

2- Proposed reaction pathway between ethamsylate and 2, 4-Dinitrofluorobenzene under the described reaction condition. 


\section{REFERENCES}

[1] Sweetman, S.C. (Ed) 2009 Martindale: The Complete Drug Reference, 36th ed., The Pharmaceutical Press, London, p. 1064 .

[2] The British Pharmacopoeia, The Stationery Office: London; Electronic version (2007).

[3] N. Kaul, H. Agrawal, A. Kakad, S.R. Dhaneshwar, B. Patil, Anal Chim Acta 536 (2005) 49-70.

[4] M. Zhang , Y. Zhang , Q. Li, Spectrochim Acta A 75 (2010)1013-1017

[5] A.Goyal, I. Singhvi, Indian J Pharm Sci. 70 (2008) 108-11.

[6] N. El-Enany, F. Belal, M. Rizk, J AOAC Int. 90 (2007) 679-685.

[7] Y. El-Shabrawy, N. El-Enany, K. Salem, Farmaco 59(2004) 803-808.

[8] Z.C. Xu, X.Y. Li, J. Shi, X.J. Yao, A.Z. Liu, Z.S. He, Fenxi Huaxue 22(1994) 420.

[9] F. Belal, A. El-Brashy, N. El-Enany, M. Tolba, J Fluoresc. 21 (2011) 1371-84.

[10] Y.S. Jaiswal, G.S. Talele, S.J. Surana, J Planar Chromatogr Mod TLC 105 (2005) 380-383.

[11] J. Ma, Y. Liu , Yaowu Fenxi Zazhi 4 (1984) 209-211.

[12] S.F. Wang, Q. Xu, Bioelectrochemistry 70 (2007) 296-300.

[13] Z.H. Wang, Z.G. Li, S.P. Zhou, Fenxi Huaxue 33 (2005) 523-526.

[14] X.H. Zhang, S.F. Wang, Sens Actuators B, 104 (2005) 29-34

[15] Z.H. Wang, D. Zhang, Y. Zhang, S.P. Zhou, Fenxi Huaxue 29 (2001) 83-86.

[16] F.Z. Yang, C. Zhang, W.R.G. Baeyens, X.R. Zhang, J Pharm Biomed Anal. 30 (2002) 473-478.

[17] ] Y.H. Li, J.X. Du, J.R. Lu, Fenxi Huaxue 30 (2002) 742-744.

[18] J.X. Du, Y.H. Li, Y.Tang, J.R. Lu, Anal Lett. 35 (2002) 463-472.

[19] C.X. Zhang, J.C. Huang, M.L. Feng, Z.J. Zhang, Anal Lett. 31 (1998) 1917-1928.

[20] J.Li, H.Ju, Electrophoresis 27 (2006) 3467-3474.

[21] I. A. Darwish, Anal Chim Acta 551(2005) 222-231.

[22] Q. Li, H.Zhang, Spectrochim Acta A 70 (2008) 284-9.

[23] H. Y. Wang, L.X. Xu, Y. Xiao, J. Han, Spectrochim Acta A 60 (2004) 2933-9.

[24] I. A. Darwish, M. M. Al-Shehri, M. A. El-Gendy, Chem Centr J (2012) 6:11.

[25] M. I. Walash, F. F. Belal, N. M. El-Enany, N. M. El-Maghrabey, Chem Cent J 5 (2011) 36.

[26] ICH Harmonized Tripartite Guideline, Validation of analytical procedures: Text and Methodology, Q2(R1), Current Step 4 Version, Parent Guidelines on Methodology Dated November 6 1996, Incorporated in November 2005.

http://www.bioforum.org.il/Uploads/Editor/karen/q2_r1_step4.pdf (accessed February15, 2010).

[27] J. N. Miller, J. C. Miller, Statistics and chemometrics for Analytical Chemistry, 5th ed. Prentice Hall, England, (2005) 256.

[28] Rose, J. Advanced Physico-Chemical experiments. Pitaman, London, (1964) p. 67. 